\title{
Evaluation of adaptive facades: The case study of Al Bahr Towers in the UAE
}

\author{
Shady Attia*
}

Argenco, University of Liège, Liège, Belgium

*Email: shady.attia@ulg.ac.be

http://dx.doi.org/

10.5339/qproc.2016.qgbc.8

(c) 2016 Attia, licensee HBKU Press. This is an open access article distributed under the terms of the Creative Commons Attribution license CC BY 4.0, which permits unrestricted use, distribution and reproduction in any medium, provided the original work is properly cited.

\begin{abstract}
The assessment of adaptive facades presents a barrier in light of the fact that there are no standard assessment techniques to systematically achieve this goal. Most of the available facade performance evaluation systems or frameworks have limited applicability for such advanced building facades.

The complexity involved in the evaluation of adaptive or dynamic facades is related to the performance evaluation of facade elements, systems and overall building performance associated with occupant behavior and occupant satisfaction. In this context, we present a case study of an adaptive sunscreen facade to evaluate its performance and occupant behavior. The evaluation focuses mainly on the preand post-construction phases of adaptive facades: the design assist phase (including the durability test, visual mockup, onsite mashrabiya mounting and weather stripping), the commissioning phase (field verification and performance testing) and the monitoring phase. The selected project is a 150-meter-high twin tower that stands with a honeycomb-inspired structure and an automated dynamic solar screen that responds to the sun's movement. These solar screens respond dynamically and automatically to the angle of the sun that improves the control over energy consumption, solar radiation and glare with the ability to allow natural light into the building. This paper is part of the research activities of working group 3 of the European COST Action 1403 on "Adaptive Facades". Different methods were used for evaluation, which include: interviews with the architect, facade engineer, technical control specialist and occupants; reviews of standards and codes; and reviews of energy models and a systematic design process mapping. A documentation of the case study describing the post-construction occupant comfort and facade operation was prepared. The audience of this paper is mainly project managers, architects, building facade engineers as well as facility managers concerned with the process of design, construction and operation of adaptive sunscreen facades. The outcome of this study identifies quantifiable performance indicators and effective strategies for the design and performance evaluation of optimal adaptive facades.
\end{abstract}

Keywords: Sunscreens, occupant behavior, occupant comfort, solar gain, daylight, operation and control, service life
Cite this article as: Attia S. Evaluation of adaptive facades: The case study of Al Bahr Towers in the UAE. QScience Proceedings: Vol. 2016, Qatar Green Building Conference 2016 - The Action, 8. http://dx.doi.org/10.5339/qproc.2016.qgbc.8 